\title{
Diet-induced obesity in rats leads to a decrease in sperm motility
}

\author{
Carla DB Fernandez ${ }^{1,2^{*}}$, Fernanda F Bellentani ${ }^{2}$, Glaura SA Fernandes ${ }^{1,2}$, Juliana E Perobelli, ${ }^{1,2}$, \\ Ana Paula A Favareto ${ }^{1,2}$, André F Nascimento ${ }^{3}$, Antonio C Cicogna ${ }^{3}$, Wilma DG Kempinas ${ }^{2}$
}

\begin{abstract}
Background: Obesity is rapidly becoming a worldwide epidemic that affects children and adults. Some studies have shown a relationship between obesity and infertility, but until now it remains controversial. Thus, the aim of the present study was to investigate the effect of high-fat diet-induced obesity on male reproductive parameters.

Methods: In a first experiment, male Wistar rats were fed a high-fat diet (HFD) or standard chow (SD) for 15, 30 or 45 weeks, after which they were evaluated by adiposity index, serum leptin levels, reproductive organ weights and sperm counts. In a second experiment, rats received HFD or SD only for 15 weeks, long enough to cause obesity. Sexual hormones and sexual behavior were evaluated in these animals, as well as fertility after natural mating. Another group of rats was submitted to motility analysis and fertility evaluation after in utero insemination.

Results: After 15, 30 or 45 weeks, HFD-fed animals presented significant increases in obesity index and serum leptin levels. Reproductive organ weights and sperm counts in the testis and epididymis were similar between the two groups at all timepoints studied. Sexual behavior was not altered by the diet regimen, and HFD fertility after natural mating was also similar to SD-fed animals. Intergroup testosterone levels were also comparable, but estradiol levels were increased in HFD rats. Furthermore, sperm quality was reduced in HFD animals as evidenced by their decreased percentage of sperm with progressive movement. This altered motility parameter was followed by a trend toward reduction in fertility potential after artificial in utero insemination.
\end{abstract}

Conclusions: The results reported herein showed that obesity can affect sperm quality, by reducing sperm motility, without affecting other sperm parameters. The low sperm quality caused a slight reduction in fertility potential, showing that obesity may lead to impairment in male fertility.

\section{Background}

Overweight and obesity constitute a health problem of increasing prevalence and present a major public health concern [1,2] that affects men and women, young and old [3]. These two statuses are often defined simply as a condition of abnormal or excessive fat accumulation in adipose tissue [4] arising from an imbalance between calories ingested versus calories expended [5]. The change in the average weight of the population is occurring quickly, and within a few generations the bell-curve of human-weight distribution has shifted toward greater weight [3].

\footnotetext{
* Correspondence: carladbf@yahoo.com.br

${ }^{1}$ Graduate Program in Cell and Structural Biology, Institute of Biology,

University of Campinas (UNICAMP), Campinas, SP, Brazil

Full list of author information is available at the end of the article
}

Obesity is a risk factor for non-insulin-dependent diabetes, cardiovascular disease, osteoarthritis, some types of cancer, and certain reproductive and metabolic disorders [6]. It is also associated with disturbance in the hormonal milieu that can affect the reproductive system, which is clear in women who present reproductive disorders when obese $[7,8]$. However, in men this relationship is poorly characterized, due to the lower number of studies in the literature [2,9]. In recent years, some studies have associated the body mass index (BMI) with reproductive parameters in men, showing that increased BMI is related to poor semen quality [10], decreased sperm concentration [11], decreased normal-motile sperm cells and increased DNA fragmentation index [12]. On the other hand, some works showed little or no relation between obesity and sperm concentration 
[2,13], motility or morphology [2] in men, even when serum reproductive hormone levels are altered [2,13].

A small number of energy-balance genes are known to be essential for normal body regulation and a loss-offunction mutation in a single gene can lead to obesity in laboratory animals [14]. However, it does not explain obesity in the majority of the human population where no such genetic changes have been identified. If obesity were entirely genetic in causation, it would be difficult to explain the increased in prevalence of obesity over the last few decades. Contemporary diets are a major factor in the current obesogenic environment, and most human obesity could probably be assessed as being dietinduced [14]. Although genetic obesity models are useful for finding the role of endogenous neuropeptides in body weight control, the best parallels to human obesity are provided by the physiological model of diet-induced obesity (DIO) [14,15].

In diet-induced obese male mice decreases in sperm motility [16,17], fertilization rate [17] number of plugs and pregnancy rate [16], as well as increases in sperm DNA damage and sperm intracellular reactive oxygen species (ROS) have been reported [17]. However, Tortoriello and colleagues [18] found no impairment in the fertility of male DBA/2J mice after they were fed a high-fat diet. In studies of rats made obese by cafeteria feeding, a diminished number of ejaculations was observed [19]. Thus, in the literature, few studies report the effects of obesity on male fertility and sperm quality and the results are altogether less clear. Therefore the aim of this study was to determine the effect of high-fat diet-induced obesity on reproductive parameters in male rats.

\section{Methods}

Animals

Male (aged 5-6 weeks) and female (aged 11-12 weeks) Wistar rats were supplied by São Paulo State University Animal Center - UNESP - Botucatu/SP. During the experiment, animals were allocated individually into polypropylene cages, with laboratory grade pine shavings as bedding. Rats were maintained under controlled temperature $\left( \pm 23^{\circ} \mathrm{C}\right)$ and lighting conditions $(12 \mathrm{~L}, 12 \mathrm{D}$ photoperiod, lights switched off at 07:00am). Rat chow and filtered tap water were provided ad libitum. Experimental procedures were in accordance with the Ethical Principles in Animal Research adopted by the Brazilian College of Animal Experimentation and were approved by the Biosciences Institute/UNESP Ethics Committee for Animal Research (protocol number 06/07).

\section{Experimental design}

Male rats were randomly assigned to one of two different groups: the first was fed a high-fat diet, with a content of $20 \%$ fat (RC Focus 2413 Agroceres ${ }^{\circledR}$, Rio Claro,
São Paulo, Brazil) and the second received a standard diet with 4\% fat content (RC Focus 1765 Agroceres ${ }^{\circledR}$, Rio Claro, São Paulo, Brazil). The dietary regimen was adapted from previous studies [20,21].

The study was divided into two steps. In the first (experiment 1), rats were given the high-fat diet (HFD) or standard diet (SD) for 15,30 or 45 weeks. In the second step (experiment 2) the animals were exposed to HFD or SD for a period of 15 weeks, long enough to increase adiposity index, which characterizes obesity.

\section{Experiment 1}

\section{Collection of tissue and organs}

In this part of the study rats were given a high-fat diet (HFD) or standard diet (SD) for 15, 30 or 45 weeks. Rats were weighed every week, and food consumption was monitored daily. After each period of diet exposure, rats ( $\mathrm{n}=9-13 /$ group/food exposure time) were slightly anesthetized with sodium pentobarbital ip $(40 / \mathrm{mg} / \mathrm{kg})$, weighed and killed by decapitation. Blood was collected from the ruptured cervical vessels for determination of leptin levels. Adipose tissue was isolated and weighed from the epididymal, visceral and retroperitoneal pad. The right testis, epididymis, vas deferens, ventral prostate and seminal vesicle (without the coagulating gland) were removed and their weights (absolute and relative to body weights) were determined. Testis and epididymis were used for sperm counts.

\section{Adiposity index}

Adiposity index was determined by the sum of epididymal, visceral and retroperitoneal fat weights divided by body weight $\times 100$, and expressed as adiposity percentage [22].

\section{Daily sperm production per testis, sperm number and transit time in the epididymis}

Homogenization-resistant testicular spermatids (stage 19 of spermiogenesis) in the testis were counted as described previously by Robb et al. [23], with adaptations adopted by Fernandes et al. [24]. Briefly, the testis, decapsulated and weighed soon after collection, was homogenized in $5 \mathrm{~mL}$ of $\mathrm{NaCl} 0.9 \%$ containing Triton $\times 1000.5 \%$, followed by sonication for 30 seconds. After a 10-fold dilution, one sample was transferred to Neubauer chambers (4 fields per animal), and late spermatids were counted. To calculate the daily sperm production (DSP), the number of homogenization-resistant spermatids was divided by 6.1 , the number of days these spermatids are present in the seminiferous epithelium. In the same manner, caput/corpus and cauda epididymidis portions were cut into small fragments with scissors and homogenized, and sperm counted as described for the testis. The sperm transit time through the epididymis was determined by dividing the number of sperm in each portion by the DSP. 


\section{Experiment 2}

In this part of the study, animals were exposed to the high-fat or standard diet for 15 weeks, a period sufficient to characterize obesity. Rats were weighed every week, and food consumption was monitored daily. After the period of diet exposure, a group of rats (12-13/ group) was assessed for sexual behavior and fertility outcomes after natural mating. Then, 15 days after the end of the sexual behavior test, rats were slightly anesthetized with sodium pentobarbital ip $(40 \mathrm{mg} / \mathrm{Kg}$ ), weighed and killed by decapitation. Blood was collected from the ruptured cervical vessels for determination of sexual hormone levels (testosterone, follicle stimulating hormone - FSH, luteinizing hormone - LH, estradiol). Three fat deposits - epididymal, visceral and retroperitoneal - were removed and weighed, as already described. Semen was collected from the right and left deferens ducts to evaluate sperm motility and sperm morphology, respectively. The right testes were collected for in vitro testosterone assay. Another group of rats (11/group), exposed to the different diets as previously described, had fertility tested by in utero artificial insemination.

\section{Serum testosterone, FSH, LH and estradiol levels}

The serum was obtained by centrifugation $(2400 \mathrm{rpm}$, for 20 minutes at $4^{\circ} \mathrm{C}$ ) and the concentrations of testosterone, estradiol, luteinizing hormone (LH) and folliclestimulating hormone (FSH) were determined by the technique of double antibody radioimmunoassay. Testosterone doses were accomplished by using the TESTOSTERONE MAIA ${ }^{\circledR}$ kit (Biochem Immuno System). The LH and FSH doses used specific kits supplied by the National Institute of Arthritis, Diabetes and Kidney Diseases (NIADDK, USA). All samples were dosed in the same assay to avoid inter-assay errors. The intraassay error was $3.4 \%$ for $\mathrm{LH}, 2.8 \%$ for $\mathrm{FSH}$ and $4 \%$ for testosterone.

\section{Evaluation of sexual behavior and natural mating}

At the end of the 15-week diet exposure, male rats from each experimental group were placed individually in polycarbonate crystal boxes, measuring $44 \times 31 \times$ $16 \mathrm{~cm}, 5 \mathrm{~min}$ before introduction of one adult female rat in natural estrus (sexually receptive) determined by vaginal smear. The animals were observed in the dark period of the cycle in a separate room under dim red light, and all sexual behavior tests were performed $2-4 \mathrm{~h}$ after the beginning of the dark period. For the next 40 min the following parameters were evaluated: latency to the first mount, intromission and ejaculation; number of intromissions until the first ejaculation; latency of the first post ejaculatory intromission; number of post ejaculatory intromissions; and number of ejaculations $[25,26]$. The males that did not mount in the initial 10 min were considered sexually inactive.
After the sexual behavior test the couples were kept together for an additional 4 hours. The animals that had been deemed inactive were tested one more time, for fertility, with different females in estrus. At the end of the afternoon males and females were separated and vaginal smears were collected. The day on which sperm were found in the smear was determined to be gestational day 0 (GD0); females were killed 20 days later to evaluate fertility.

\section{Sperm motility and morphology}

Immediately after euthanasia, the right vas deferens was collected. Sperm were obtained with the aid of a syringe and needle, through internal rinsing with $1.0 \mathrm{~mL}$ of modified HTF medium (Human Tubal Fluid, IrvineScientific) at $34^{\circ} \mathrm{C}$. A Makler counting chamber (Sefi-Medical, Haifa, Israel) warmed to $34^{\circ} \mathrm{C}$ was loaded with a small aliquot of sperm solution. Sperm motility evaluation was performed by the same person throughout the study and was assessed by visual estimation (100 spermatozoa per animal, in duplicate) under a phase-contrast microscope (Leica DMLS) at 200X magnification. Spermatozoa were classified as: immotile, motile without progression and motile with progressive movement. Sperm were also removed from the left vas deferens by internal rinsing with $1.0 \mathrm{~mL}$ of saline formol, with the aid of a syringe and needle. To analyze sperm morphology, smears were prepared on histological slides that were left to dry for $90 \mathrm{~min}$ and observed in a phase-contrast microscope (400 $\times$ magnification) [27], and 200 spermatozoa were analyzed per animal. Morphological abnormalities were classified into two general categories pertaining to head morphology (without curvature, without characteristic curvature, pin head or isolated form, i.e., no tail attached) and tail morphology (broken, isolated, i.e., no head attached or rolled into a spiral) [28].

\section{Intratesticular testosterone concentration}

The right testis of each animal was removed and decapsulated, and the parenchyma was sliced into $\sim 50-\mathrm{mg}$ pieces. Each piece was weighed and placed into a $1.5-\mathrm{ml}$ micro tube containing $1.0 \mathrm{ml}$ of Medium 199 (M199). The M199 was buffered with $0.71 \mathrm{~g} / \mathrm{L}$ sodium bicarbonate $(\mathrm{NaHCO} 3)$ and $2.1 \mathrm{~g} / \mathrm{L}$ Hepes, and contained $0.1 \%$ BSA (bovine serum albumine) and $25 \mathrm{mg} / \mathrm{L}$ soybean trypsin inhibitor, $\mathrm{pH}$ 7.4. Testosterone concentration was assessed by incubating parenchyma in duplicate, for $2 \mathrm{~h}$ at $34^{\circ} \mathrm{C}$ [29]. After centrifugation $(5 \mathrm{~min}, 10.000 \times \mathrm{g}$ ), medium was frozen at $-70^{\circ} \mathrm{C}$ until testosterone assay, which was performed as described previously.

\section{In utero artificial insemination}

Because rats produce and ejaculate an excess of qualitatively normal sperm, artificial in utero insemination of a fixed critical number of sperm has been suggested as a means of increasing the sensitivity of a toxicant-induced 
decrease in sperm quality in the rat [30]. According to this technique, a fixed number of sperm collected from the cauda epididymis is inseminated directly into the uterus allowing evaluation of sperm quality, without the interference of other factors such as alterations of the sexual behavior pattern and number of sperm available for ejaculation [31].

A cohort of females $(n=40)$ was synchronized with a single subcutaneous injection of $80 \mu \mathrm{g}$ of luteinizing releasing hormone (LHRH) agonist (Sigma Chemical Co., St Louis, Missouri), 115 hours prior to the insemination. Shortly after the room lights were turned off on the day of proestrus, the synchronized females were paired with sexually experienced, vasectomized males of proven sterility for $1 \mathrm{~h}$. Receptive females (that exhibited lordosis) were selected for insemination. The isolation and preparation of proximal cauda sperm for insemination were the same as described previously [32,33], with the following adaptations. Briefly, the sperm were released from the proximal cauda by nicking the tubule with a n 11 scalpel and allowed to disperse in $2 \mathrm{ml}$ of modified HTF medium (Human Tubular Fluid, IrvineScientific $\left.^{\circledR}\right)$. After $5 \mathrm{~min}$ of dispersion, a sperm aliquot was diluted 1:10 with fixative (10\% formalin in PBS) and counted using a Neubauer chamber. Within $15 \mathrm{~min}$, each uterine horn was injected with a volume containing $5 \times 10^{6}$ sperm [32]. One female was inseminated per male. All inseminations were performed while the recipient female was in a surgical plane using a mix of ketamine and xylazine anesthesia. The bifurcation of the uterine horns was exposed through a low, midventral incision. Fine curved forceps were used to elevate each horn while the insemination volume was injected through the wall of each horn via an 18-gauge i.v. catheter attached to a 1.0-ml syringe. Each injection site was cauterized immediately upon withdrawal of the needle. When insemination was completed, the abdominal musculature was sutured. Females were killed 20 days later to evaluate fertility.

\section{Fertility evaluation}

On the GD20 the females that had been naturally and artificial inseminated were killed by decapitation. After collection of the uterus and ovaries the numbers of corpora lutea, implants, reabsorptions and live and dead fetuses were determined. From these results the following parameters were calculated: gestation rate: number of pregnant females/number of inseminated females $x$ 100; fertility potential (efficiency of implantation): implantation sites/corpora lutea $\times 100$; rate of preimplantation loss: [number of corpora lutea - number of implantations/number of corpora lutea] $\times 100$; and rate of postimplantation loss: [number of implantations number of live fetuses]/number of implantations $\times 100$.

\section{Statistical Analysis}

Two-way ANOVA for independent groups followed by the post hoc Tukey test were performed for comparison of results among the experimental groups in experiment 1. For experiment 2 Student t test or nonparametric Mann-Whitney test were used according to the characteristics of each variable. Differences were considered significant when $\mathrm{p}<0.05$.

\section{Results \\ Experiment 1}

Throughout the course of the study, the mean food intake of HFD rats was significantly lower than the mean food intake of SD rats, in all experimental periods. In contrast, total caloric consumption between the groups was similar at 15 weeks (HFD = SD) and elevated at 30 and 45 weeks (HFD > SD) (Table 1). Body weight, fat deposits, adiposity index and serum leptin increased significantly in a time-dependent manner in obese and control animals but were higher in the obese group (HFD > SD) (Table 2).

Reproductive organs weights did not show any differences between HFD and SD groups in all treatment periods, excepting the relative weight of empty seminal vesicle which was lower in HFD animals than in SD after 45 weeks of diet exposure (Table 3 ). When animals from different timepoint were compared, differences were found even among control groups (Table 3).

There was no statistically significant difference between SD and HFD groups related to the number of mature spermatids in the testis and daily sperm production (Table 4). When animals were compared in relation to time, the number of mature spermatids in the testis was lower in 30 and 45-weeks animals in both experimental groups. In the epididymis the number of spermatozoa in caput/corpus was similar between SD and HFD groups in all periods of diet exposure, but in epididymal cauda of animals fed HFD for 30 weeks there was an increase in sperm number compared to SD animals in this timepoint (Table 4). The sperm transit time did not show any difference between SD and HFD either in epididymal caput/corpus or cauda (Table 4).

\section{Experiment 2}

As occurred in experiment 1, HFD rats showed a statically significant increase in adiposity index, body weight and weights of fat deposits (data not shown) after 15 weeks of diet exposure.

Sexual behavior, assessed in this experiment, was not exhibited by some of the animals (2/13 in SD and 2/14 in HFD). Among those who presented sexual behavior, HFD animals showed an increase $(\mathrm{p}<0.05)$ in latency to the first mount and a decrease $(p<0.05)$ in the 
Table 1 Daily mean food and calories consumption in rats from SD and HFD groups

\begin{tabular}{lcccccc}
\hline & \multicolumn{2}{c}{$\mathbf{1 5}$ weeks } & \multicolumn{2}{c}{30 weeks } & \multicolumn{2}{c}{ 45 weeks } \\
& SD & HFD & SD & HFD & SD & HFD \\
\hline Daily food intake $(\mathrm{g})$ & $28.6 \pm 0.4^{\mathrm{Aa}}$ & $22.5 \pm 0.3^{\mathrm{ABb}}$ & $27.1 \pm 0.3^{\mathrm{Ba}}$ & $23.1 \pm 0.3^{\mathrm{Ab}}$ & $26.5 \pm 0.2^{\mathrm{Ba}}$ & $22.0 \pm 0.2^{\mathrm{Bb}}$ \\
Daily calories intake (kcal) & $90.5 \pm 1.2^{\mathrm{Aa}}$ & $91.8 \pm 1.2^{\mathrm{ABa}}$ & $85.5 \pm 1.0^{\mathrm{Ba}}$ & $94.4 \pm 1.0^{\mathrm{Ab}}$ & $83.8 \pm 0.7^{\mathrm{Ba}}$ & $89.7 \pm 0.7^{\mathrm{Bb}}$ \\
$N$ & 11 & 13 & 12 & 11 & 11 & 9 \\
\hline
\end{tabular}

Data expressed as means \pm SEM. The capital letters refer to comparison between times, while lower case letters refer to the comparison between SD and HFD groups. Different letters indicate a significant difference ( $p<0.05$, Two-Way ANOVA, post hoc Tukey Test).

number of intromissions after the first ejaculation. The other parameters evaluated in the test were similar between the two groups (Table 5).

Serum testosterone, FSH and LH levels were similar between SD and HFD animals; furthermore, parenchyma testosterone was not affected in HFD rats compared to SD animals. On the other hand, estradiol levels were significantly higher in HFD-fed animals (Table 6).

Results obtained from the morphological assessment of spermatozoa indicated that the percentages of both abnormal and normal sperm were similar between SD and HFD rats $[\mathrm{SD}=94(91-97) \%$ and HFD $=93$ (91-95)\%, median (Q1-Q3) values for normal sperm]. The percentage of sperm with progressive movement was significantly diminished $(\mathrm{p}<0.05)$ and the percentage of sperm without progressive movement was elevated $(\mathrm{p}<0.05)$ in the HFD group when compared to SD animals (Figure 1).

The gestational rate was one hundred percent in both groups after natural mating, and thus there were no differences between SD and HFD groups regarding any fertility parameters (Table 7). After the in utero artificial insemination, the gestational rate was $100 \%$ in SD group and $78 \%$ in HFD. Fertility potential showed a tendency to decrease whereas the pre-implantation loss rate tended to increase in HFD animals, but without statistical significance (Table 7).

\section{Discussion}

It is believed that with the increasing prevalence of sedentary lifestyles and dietary changes, obesity is emerging, in turn, as an important cause of adverse health outcomes, including male infertility [34]. Data from different population studies show an inverse relationship between BMI (body mass index) and fertility $[10,11]$, although the mechanism by which fertility is affected is still unclear [35].

In an attempt to achieve deeper knowledge about obesity, several animal models have been developed, among which rodent models of diet-induced obesity (DIO) may provide the best parallels in relation to human obesity $[14,15,18]$. In this study, an obesity model induced by high-fat diet consumption was chosen. It is cited in the literature as causing obesity in a variety of mammals including nonhuman primates, dogs, pigs, hamsters, squirrels, mice [36], and rats [36,37].

The high-fat diet used in the present study was effective in promoting obesity, as demonstrated by an increased adiposity index in association with a higher body weight. This condition was exacerbated by long-term ingestion of a high-fat diet. The obese state was related to higher caloric intake in the HFD group at 30 and 45 weeks; however, obesity also was evident at 15 weeks even in the absence of higher caloric consumption by HFD rats. This condition may have been due to a high feeding effectiveness ratio in the hyperlipidic diet. There is evidence that high fat consumption is not accompanied by a proportional increase in its oxidation. This phenomenon favors the deposition of lipids such as triacylglycerol in adipose tissue, leading to an increase in body weight $[38,39]$. Unfortunately, there is no established threshold to differentiate obesity from

Table 2 Body weight, fat weighs and leptin levels in rats from SD and HFD groups

\begin{tabular}{|c|c|c|c|c|c|c|}
\hline & \multicolumn{2}{|c|}{15 weeks } & \multicolumn{2}{|c|}{30 weeks } & \multicolumn{2}{|c|}{45 weeks } \\
\hline & SD & HFD & SD & HFD & SD & HFD \\
\hline Final body weight (g) & $468.36 \pm 5.58^{\mathrm{Aa}}$ & $502.31 \pm 8.41^{\mathrm{Ab}}$ & $533.08 \pm 8.44^{\mathrm{Ba}}$ & $583.09 \pm 13.00^{\mathrm{Bb}}$ & $567.82 \pm 13.18^{\mathrm{Ba}}$ & $644.22 \pm 20.43^{\mathrm{Cb}}$ \\
\hline \multicolumn{7}{|l|}{ Fat deposits (g) } \\
\hline Epididymal & $7.85 \pm 0.31^{\mathrm{Aa}}$ & $10.67 \pm 0.69^{A b}$ & $8.90 \pm 0.73^{\mathrm{Aa}}$ & $12.87 \pm 1.29^{\mathrm{Ab}}$ & $12.77 \pm 1.05^{\mathrm{Ba}}$ & $16.84 \pm 1.08^{\mathrm{Bb}}$ \\
\hline Visceral & $4.98 \pm 0.36^{\mathrm{Aa}}$ & $7.08 \pm 0.59^{\mathrm{Ab}}$ & $5.62 \pm 0.43^{\mathrm{Aa}}$ & $9.46 \pm 0.95^{\mathrm{Ab}}$ & $9.32 \pm 0.76^{\mathrm{Ba}}$ & $13.17 \pm 1.21^{\mathrm{Bb}}$ \\
\hline retroperitoneal & $7.06 \pm 0.30^{\mathrm{Aa}}$ & $11.56 \pm 1.38^{\mathrm{Ab}}$ & $8.79 \pm 1.03^{\mathrm{Aa}}$ & $14.71 \pm 1.82^{\mathrm{Ab}}$ & $13.83 \pm 0.90^{\mathrm{Ba}}$ & $22.65 \pm 2.34^{\mathrm{Bb}}$ \\
\hline Adiposity index (\%)* & $4.22^{\mathrm{Aa}}$ & $5.78^{\mathrm{Ab}}$ & $4.35^{\mathrm{Aa}}$ & $6.26^{\mathrm{Ab}}$ & $6.30^{\mathrm{Ba}}$ & $8.09^{\mathrm{Bb}}$ \\
\hline Leptin levels (ng/mL) & $2.88 \pm 0.28^{\mathrm{Aa}}$ & $5.42 \pm 0.34^{\mathrm{Ab}}$ & $4.98 \pm 0.41^{\mathrm{Ba}}$ & $8.17 \pm 0.80^{\mathrm{Bb}}$ & $7.32 \pm 0.77^{\mathrm{Ca}}$ & $10.92 \pm 0.93^{\mathrm{Cb}}$ \\
\hline$N$ & 11 & 13 & 12 & 11 & 11 & 9 \\
\hline
\end{tabular}

Data expressed as means \pm SEM. The capital letters refer to comparison between times, while lower case letters refer to the comparison between SD and HFD groups. Different letters indicate a significant difference ( $p<0.05$, Two-Way ANOVA, post hoc Tukey Test).

${ }^{*}$ Adiposity index values were transformed in arc sen prior to statistical analysis and they are expressed as mean. 
Table 3 Absolute and relative organs weight in rats from SD and HFD groups

\begin{tabular}{|c|c|c|c|c|c|c|}
\hline & \multicolumn{2}{|c|}{15 weeks } & \multicolumn{2}{|c|}{30 weeks } & \multicolumn{2}{|c|}{45 weeks } \\
\hline & SD & HFD & SD & HFD & SD & HFD \\
\hline \multicolumn{7}{|l|}{ Absolute organs weight } \\
\hline Testis (g) & $1.88 \pm 0.04^{\mathrm{Aa}}$ & $1.82 \pm 0.06^{\mathrm{Aa}}$ & $1.74 \pm 0.11^{\mathrm{Aa}}$ & $1.91 \pm 0.06^{\mathrm{Aa}}$ & $1.94 \pm 0.05^{\mathrm{Aa}}$ & $2.12 \pm 0.11^{\mathrm{Aa}}$ \\
\hline Epididymis (mg) & $666.73 \pm 14.77^{\mathrm{Aa}}$ & $671.69 \pm 14.87^{\mathrm{Aa}}$ & $629.33 \pm 34.61^{\mathrm{Aa}}$ & $668.55 \pm 18.35^{\mathrm{Aa}}$ & $646.45 \pm 14.75^{\mathrm{Aa}}$ & $683.78 \pm 40.45^{\mathrm{Aa}}$ \\
\hline Vas deferens (mg) & $99.73 \pm 2.81^{\mathrm{Aa}}$ & $98.41 \pm 6.29^{\mathrm{Aa}}$ & $116.17 \pm 4.97^{\mathrm{Aa}}$ & $114.00 \pm 5.52^{\mathrm{Aa}}$ & $119.73 \pm 4.14^{\mathrm{Ba}}$ & $130.11 \pm 3.71^{\mathrm{Ba}}$ \\
\hline Ventral prostate (mg) & $478.91 \pm 43.43^{\mathrm{ABa}}$ & $542.54 \pm 37.14^{\mathrm{ABa}}$ & $588.75 \pm 29.11^{\mathrm{Aa}}$ & $556.55 \pm 32.37^{\mathrm{Aa}}$ & $418.18 \pm 39.68^{\mathrm{Ba}}$ & $417.89 \pm 32.18^{\mathrm{Ba}}$ \\
\hline Seminal vesicle full (g) & $1.24 \pm 0.08^{\mathrm{Aa}}$ & $1.37 \pm 0.09^{\mathrm{Aa}}$ & $1.36 \pm 0.09^{\mathrm{Aa}}$ & $1.48 \pm 0.07^{\mathrm{Aa}}$ & $1.46 \pm 0.07^{\mathrm{Aa}}$ & $1.59 \pm 0.07^{\mathrm{Aa}}$ \\
\hline Seminal vesicle empty (mg) & $578.36 \pm 38.34^{\mathrm{Aa}}$ & $658.62 \pm 30.83^{\mathrm{Aa}}$ & $728.83 \pm 59.15^{\mathrm{Ba}}$ & $745.00 \pm 34.09^{\mathrm{Aa}}$ & $703.73 \pm 33.48^{\mathrm{ABa}}$ & $680.89 \pm 43.02^{\mathrm{Aa}}$ \\
\hline \multicolumn{7}{|l|}{ Relative organs weight } \\
\hline Testis (g/100 g) & $0.40 \pm 0.01^{\mathrm{Aa}}$ & $0.36 \pm 0.01^{\mathrm{Aa}}$ & $0.34 \pm 0.02^{\mathrm{Ba}}$ & $0.33 \pm 0.01^{\mathrm{Aa}}$ & $0.34 \pm 0.01^{\mathrm{Ba}}$ & $0.32 \pm 0.02^{\mathrm{Aa}}$ \\
\hline Epididymis (mg/100 g) & $141.44 \pm 3.41^{\mathrm{Aa}}$ & $133.93 \pm 3.03^{\mathrm{Aa}}$ & $121.46 \pm 5.48^{\mathrm{Ba}}$ & $115.52 \pm 4.93^{\mathrm{Ba}}$ & $114.21 \pm 2.90^{\mathrm{Ba}}$ & $107.49 \pm 8.21^{\mathrm{Ba}}$ \\
\hline Vas deferens (mg/100 g) & $21.16 \pm 0.62^{\mathrm{Aa}}$ & $19.68 \pm 1.25^{\mathrm{Aa}}$ & $21.97 \pm 0.98^{\mathrm{Aa}}$ & $19.59 \pm 0.86^{\mathrm{Aa}}$ & $21.23 \pm 0.96^{\mathrm{Aa}}$ & $20.37 \pm 0.97^{\mathrm{Aa}}$ \\
\hline Ventral prostate $(\mathrm{mg} / 100 \mathrm{~g})$ & $101.90 \pm 9.58^{\mathrm{Aa}}$ & $107.74 \pm 7.01^{\mathrm{Aa}}$ & $111.11 \pm 5.43^{\mathrm{Aa}}$ & $96.49 \pm 6.76^{\mathrm{Aa}}$ & $74.30 \pm 7.54^{\mathrm{Ba}}$ & $65.72 \pm 6.09^{\mathrm{Ba}}$ \\
\hline Seminal vesicle full (g/100 g) & $0.26 \pm 0.02^{\mathrm{Aa}}$ & $0.27 \pm 0.02^{\mathrm{Aa}}$ & $0.26 \pm 0.02^{\mathrm{Aa}}$ & $0.26 \pm 0.01^{\mathrm{Aa}}$ & $0.26 \pm 0.01^{\mathrm{Aa}}$ & $0.25 \pm 0.01^{\mathrm{Aa}}$ \\
\hline Seminal vesicle empty (mg/100 g) & $122.55 \pm 7.92^{\mathrm{Aa}}$ & $130.96 \pm 5.28^{\mathrm{Aa}}$ & $140.21 \pm 11.65^{\mathrm{Aa}}$ & $127.93 \pm 5.87^{\mathrm{Aa}}$ & $123.90 \pm 5.06^{\mathrm{Aa}}$ & $105.85 \pm 6.34^{\mathrm{Aa}}$ \\
\hline N & 11 & 13 & 12 & 11 & 11 & 9 \\
\hline
\end{tabular}

Data expressed as means \pm SEM. The capital letters refer to comparison between times, while lower case letters refer to the comparison between SD and HFD groups. Different letters indicate a significant difference ( $p<0.05$, Two-Way ANOVA, post hoc Tukey Test).

overweight in animal models, such as those established by the WHO for humans [40]. It should be taken into account that in this study, the adiposity index was at least $25 \%$ higher in obese animals than in the control group at all experimental moments.

The adiposity index was calculated as the sum of the weights of the fat pads divided by body weight; this quotient represented an estimation of body fat. Results found herein for control animals are in accordance with other studies in the literature $[22,41]$ that used similar methods for fat measurement. In animal models of genetic obesity, the adiposity index is higher [41] than that found in DIO animals, because the first case represents very severe obesity.

Leptin, a hormone produced mainly by adipocytes, is involved in controlling body weight by increasing both satiety and energy expenditure $[18,35,42]$. Leptin is also related to the reproductive system $[3,43]$ through both stimulatory and inhibitory effects $[44,45]$. The leptin concentration is related to the amount and distribution of body fat [6] such that the heavier the body weight the higher the leptin concentration in human and rodents [42]. The elevated serum leptin levels observed in the current study are likely a consequence of the increased fat accumulation. This result corroborates other studies in the literature that show high leptin levels in models of rodent DIO obesity $[16,18,35,44,46,47]$.

Few studies in the literature relate organ weight to obesity. In Zucker rats, a genetic model of obesity, obese animals show no difference in the weights of testes or ventral prostate compared with lean rats [48]. Similarly, DIO male mice exhibited no changes in the average weight of the testis or epididymis [16]. These data are in accordance with the results of present study.

Table 4 Sperm counts in rats from SD and HFD groups

\begin{tabular}{|c|c|c|c|c|c|c|}
\hline & \multicolumn{2}{|c|}{15 weeks } & \multicolumn{2}{|c|}{30 weeks } & \multicolumn{2}{|c|}{45 weeks } \\
\hline & SD & HFD & SD & HFD & SD & HFD \\
\hline Sperm number in the testis $\left(\times 10^{6}\right)$ & $291.70 \pm 6.02^{\mathrm{Aa}}$ & $294.02 \pm 8.25^{\mathrm{Aa}}$ & $228.42 \pm 12.30^{\mathrm{Ba}}$ & $248.05 \pm 13.56^{\mathrm{Ba}}$ & $233.92 \pm 9.64^{\mathrm{Ba}}$ & $239.54 \pm 19.73^{\mathrm{Ba}}$ \\
\hline Daily sperm production ( $\times 10^{6} /$ testis/day) & $47.82 \pm 0.99^{\mathrm{Aa}}$ & $48.20 \pm 1.35^{\mathrm{Aa}}$ & $37.45 \pm 2.02^{\mathrm{Ba}}$ & $40.66 \pm 2.22^{\mathrm{Ba}}$ & $38.35 \pm 1.58^{\mathrm{Ba}}$ & $39.27 \pm 3.24^{\mathrm{Ba}}$ \\
\hline $\begin{array}{l}\text { Sperm number in the caput/corpus } \\
\text { epididymis }\left(\times 10^{6}\right)\end{array}$ & $171.32 \pm 7.97^{\mathrm{Aa}}$ & $171.77 \pm 8.2^{\mathrm{Aa}}$ & $142.44 \pm 14.01^{\mathrm{Aa}}$ & $152.26 \pm 6.13^{\mathrm{Aa}}$ & $\begin{array}{l}172.58 \pm \\
8.99^{\text {Aa }}\end{array}$ & $162.86 \pm 18.06^{\mathrm{Aa}}$ \\
\hline $\begin{array}{l}\text { Sperm transit time in the caput/corpus } \\
\text { (days) }\end{array}$ & $3.62 \pm 0.17^{\mathrm{Aa}}$ & $3.58 \pm 0.15^{\mathrm{Aa}}$ & $4.22 \pm 0.26^{\mathrm{ABa}}$ & $3.83 \pm 0.22^{\mathrm{Aa}}$ & $4.52 \pm 0.21^{\mathrm{Ba}}$ & $4.26 \pm 0.42^{\mathrm{Aa}}$ \\
\hline $\begin{array}{l}\text { Sperm number in the cauda epididymis } \\
\left(\times 10^{6}\right)\end{array}$ & $347.61 \pm 17.72^{\mathrm{Aa}}$ & $330.30 \pm 13.3^{\mathrm{Aa}}$ & $243.82 \pm 31.46^{\mathrm{Ba}}$ & $320.94 \pm 16.77^{\mathrm{Ab}}$ & $\begin{array}{l}291.78 \pm \\
14.44^{\mathrm{ABa}}\end{array}$ & $281.57 \pm 24.61^{\mathrm{Aa}}$ \\
\hline Sperm transit time in the cauda (days) & $7.35 \pm 0.41^{\mathrm{Aa}}$ & $6.85 \pm 0.2^{\mathrm{Aa}}$ & $6.6 \pm 0.81^{\mathrm{Aa}}$ & $8.02 \pm 0.43^{\mathrm{Aa}}$ & $7.74 \pm 0.50^{\mathrm{Aa}}$ & $7.30 \pm 0.68^{\mathrm{Aa}}$ \\
\hline$N$ & 11 & 13 & 12 & 11 & 11 & 9 \\
\hline
\end{tabular}

Data expressed as means \pm SEM. The capital letters refer to comparison between times, while lower case letters refer to the comparison between SD and HFD groups. Different letters indicate a significant difference $(p<0.05$, Two-Way ANOVA, post hoc Tukey Test). 
Table 5 Sexual behavior of rats fed SD or HFD during 15 weeks

\begin{tabular}{lcc}
\hline & SD & HFD \\
\hline Latency to the first mount $(s)$ & $56.45 \pm 12.06(n=11)$ & $133.3 \pm 35.93^{*}(n=12)$ \\
Latency to the first intromission $(s)$ & $110.45 \pm 24.09(n=11)$ & $169.67 \pm 44.98(n=12)$ \\
Number of intromissions until the first ejaculation & $19.94 \pm 2.01(n=11)$ & $14.50 \pm 1.36(n=12)$ \\
Latency to the first ejaculation ( $s)$ & $664.00 \pm 68.82(n=8)$ & $946.67 \pm 123.91(n=12)$ \\
Latency to the first post-ejaculatory intromissions $(s)$ & $952.00 \pm 66.01(n=8)$ & $1234.64 \pm 142.30(n=11)$ \\
Number of post-ejaculatory intromissions & $25.75 \pm 2.2 .07(n=8)$ & $14.82 \pm 2.75^{*}(n=11)$ \\
Number of ejaculations & $2.88 \pm 0.23(n=8)$ & $2.17 \pm 0.30(n=12)$ \\
$N$ & 11 & 12 \\
\hline
\end{tabular}

Data expressed as means \pm SEM. Student $t$ test. ${ }^{*} p<0.05$.

When animals were compared in relation to time, differences were found among different timepoints, even in control animals which occurred probably due to aging process. Aging in male rats is known to be associated with some testicular alterations that result in decreased spermatogenesis and steroidogenesis [49] and gradual reduction in sperm production [50].

The number of spermatids present in the testis and the total DSP are important indicators of male fertility potential [51]. In this study, the consumption of HFD for 15, 30 or 45 weeks did not affect any of these parameters and the sperm concentration in the epididymal caput-corpus. The epididymal cauda sperm concentration was not altered in animals fed HFD for 15 and 45 weeks, which corroborates studies of male HFD-fed mice $[16,17]$. On the other hand, Sprague-Dawley rats fed a high-fat diet from 21 to 90 days old presented a reduced sperm concentration [35]. Some works show a reduction in sperm concentration in obese and overweight men $[9,11]$ while another found no alterations in sperm concentration related to BMI [2]. Animals fed HFD for 30 weeks showed an increase in epididymal cauda sperm concentration, which was probably due to a non-significant increase in sperm transit time in this segment. However, this change did not alter fertility. Although sperm transit time through the epididymis plays an important role in the maturation of spermatozoa sperm quality and fertility potential are not harmed when transit time through the epididymis is delayed $[33,52]$.

Table 6 Serum sexual hormone levels and parenchyma testosterone of rats fed SD or HFD during 15 weeks

\begin{tabular}{lcc}
\hline & SD & HFD \\
\hline Serum testosterone $(\mathrm{ng} / \mathrm{mL})$ & $1.93 \pm 0.31$ & $2.89 \pm 0.55$ \\
Serum LH $(\mathrm{ng} / \mathrm{mL})$ & $0.99 \pm 0.27$ & $0.91 \pm 0.27$ \\
Serum FSH $(\mathrm{ng} / \mathrm{mL})$ & $10.20 \pm 0.71$ & $11.97 \pm 1.74$ \\
Estradiol $(\mathrm{pg} / \mathrm{mL})$ & $8.69 \pm 0.38$ & $11.11 \pm 0.91^{*}$ \\
Parenchyma $(\mathrm{ng} / \mathrm{mg})$ & $69.50 \pm 7.72$ & $70.56 \pm 8.19$ \\
$\mathrm{~N}$ & 13 & 14 \\
\hline
\end{tabular}

Data expressed as means \pm SEM. Mann-Whitney test. ${ }^{*} p<0.05$.
In general, sexual behavior among animals fed the high-fat diet was normal, despite the delay to start the test. The normal sexual behavior observed in these animals is in concordance with their normal serum testosterone levels, which were similar to those of rats fed a standard diet. A reduction in testosterone levels expected on account of the higher leptin level in HFD animals from first experiment was not observed. Contrary to the results in the present study, Sprague-Dawley rats fed HFD from weaning to 90 days had a reduction in testosterone levels [35], and male mice fed HFD (for 9 weeks) showed a trend toward reduction in testosterone levels compared to the control group [17]. Among men, overweight and obesity is frequently related to diminished testosterone levels $[2,11,13]$, a decrease proportional to the degree of obesity [53]. The adiposity gain seen in the animals was not sufficient to produce a significant diminution in the testosterone levels, perhaps because the obesity installed was not severe; however, it was enough to provoke a significant increase in serum estradiol levels, in accordance with results found by ViguerasVillaseñor and colleagues [35]. Obesity is associated with increased estradiol levels also in men $[2,11]$.

Sperm motility is one of the most important parameters used in the evaluation of sperm quality [54-56]. This sperm parameter is acquired during sperm transit through the epididymal duct [57-61]. Epididymal histophysiology and acquisition of sperm motility are dependent on the presence of androgen $[62,63]$. In the present study the percentage of sperm with progressive motility was reduced despite normal levels of testosterone. Male mice rendered obese by consuming a high-fat diet also showed a diminished percentage of motile sperm without presenting alterations in testosterone levels [16]. In men, an inverse relationship between BMI and the number of normal-motile sperm was observed in some clinical studies [9,12], but was not found in others $[2,13]$.

Alterations in motility parameters may lead to an inefficient sperm penetration of cervix mucus [64-66], impairing the ability of sperm to reach the oocyte. In addition, a high percentage of sperm with progressive 

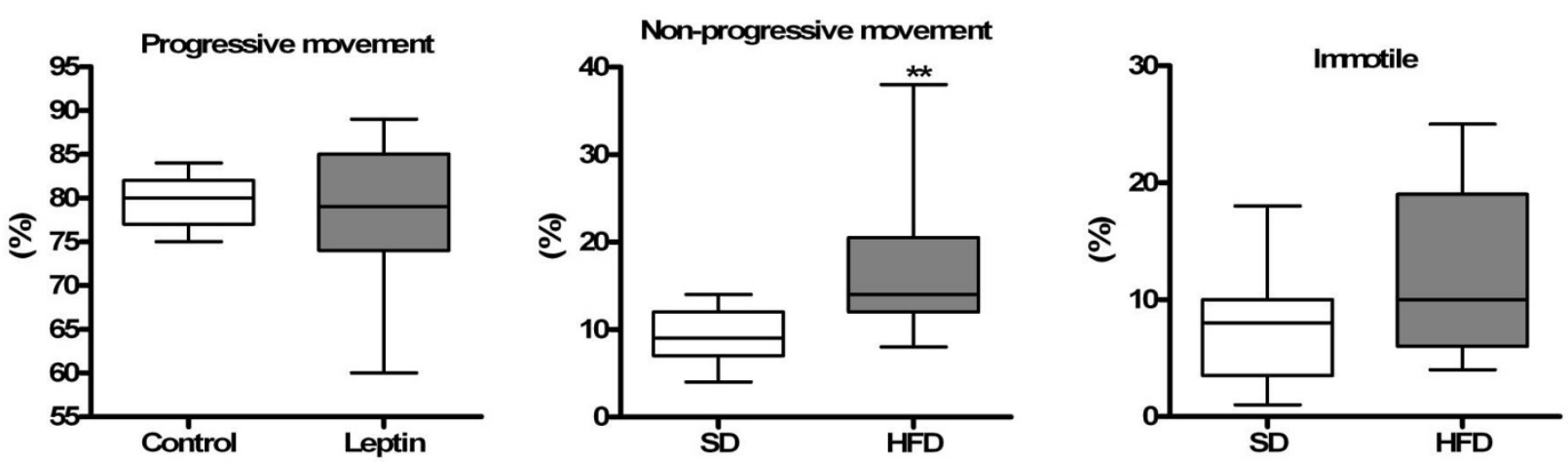

Figure 1 Sperm motility. Sperm motility of rats from SD and HFD groups. Values expressed by median. Mann-Whitney test. ${ }^{* *} p<0.001$.

motility is related to a high fertilization index [67]. Despite this, even with the decrease in progressive motility, the fertility after natural mating was not altered in HFD animals. Corroborating this result, DIO male $\mathrm{DBA} / 2 \mathrm{~J}$ mice $(24 \%$ of fat in diet) did not show any alteration in fertility in relation to lean animals [18]. Contrarily, another study found a significant reduction in fertility after natural mating of diet-induced $(60 \%$ of fat in diet) obese male C57BL/6J mice [16]. Another important sperm parameter for evaluating male fertility is sperm morphology [68] because it may indicate cytotoxic events [69]. The absence of morphological alterations in obese animals indicates a high probability that obesity did not negatively affect spermatogenesis. In the literature there is an interesting observation that spermatogenesis is affected only in males with extreme obesity [70].

Given the impairment in sperm motility and the lack of effects on fertility after natural mating in the present study, we chose to utilize artificial insemination, a technique that excludes the influence of excess sperm ejaculated [71], to detect some impairment of fertile capacity of sperm with impaired motility. Fertility potential after artificial insemination showed a trend toward reduction.
It is important to take into consideration that although the fertility potential was not significantly affected, there was a reduction of around $20 \%$ in this parameter indicating a possible reduction in fertile capacity of sperm. Similar results were found in mice by Bakos and colleagues [17], who observed a reduction in percentage of fertilized oocytes, using sperm from diet-induced obese mice (22\% fat in the diet). The absence of statistical significance in the fertility results may be due to high reproductive competence of rats, which need to show a large impairment of sperm quality to be considered infertile [72].

In summary, the results reported herein show that the HFD treatment causes obesity in rats. The obese animals present a low sperm quality, elucidated by the decreased percentage of sperm with progressive movement that tends to impair fertility without affecting other sperm parameters. The reproductive capacity of male rats is known to be higher than that of men; therefore, the decrease in sperm quality seen in obese rats was not sufficient to significantly alter their fertility, whereas such a decrease in quality may be enough to alter fertility among human males. Since obesity is a growing health problem worldwide, additional studies

Table 7 Fertility parameters after natural mating and in utero artificial insemination of rats fed SD or HFD during 15 weeks

\begin{tabular}{|c|c|c|c|c|}
\hline & \multicolumn{2}{|c|}{ Natural Mating } & \multicolumn{2}{|c|}{ In utero insemination } \\
\hline & SD & HFD & SD & HFD \\
\hline$\overline{\text { Fertility potential }(\%)^{a}}$ & $100(92.15-100)$ & $100(85.7-100)$ & $91.89(77.43-100)$ & $75.00(65.39-95.46)$ \\
\hline Body weight of dams $(g)^{b}$ & $356.67 \pm 10.67$ & $355.88 \pm 6.51$ & $314.80 \pm 12.58$ & $286.16 \pm 12.43$ \\
\hline Number of corpora lutea ${ }^{b}$ & $12.25 \pm 0.45$ & $13.15 \pm 0.37$ & $12.90 \pm 0.74$ & $11.86 \pm 0.40$ \\
\hline Number of implantation sites ${ }^{b}$ & $11.67 \pm 0.69$ & $12.38 \pm 0.40$ & $10.9 \pm 0.55$ & $8.71 \pm 1.41$ \\
\hline Number of fetuses per litter ${ }^{b}$ & $11.25 \pm 0.66$ & $10.85 \pm 1.00$ & $10.7 \pm 0.58$ & $7.86 \pm 1.41$ \\
\hline Preimplantation loss (\%) & $0(0-7.85)$ & $0(0-14.3)$ & $8.12(0-22.32)$ & $25.00(4.55-34.62)$ \\
\hline Postimplantation loss (\%) & $0(0-7.1)$ & $0(0-7.1)$ & $0(0-0)$ & $0(0-0)$ \\
\hline$N$ & 12 & 13 & 10 & 7 \\
\hline
\end{tabular}

${ }^{\mathrm{a}}$ Data expressed as median (Q1 - Q3). ${ }^{\mathrm{b}}$ Data expressed as mean \pm S.E.M. Mann-Whitney test. $\mathrm{p}>0.05$. 
are needed to investigate more deeply the relationship between obesity and male infertility.

\section{Acknowledgements}

The authors are grateful to Dr. Janete Aparecida Anselmo Franci and Dr. Ruither de Oliveira Gomes Carolino for the hormonal dosages. We are also grateful to José Eduardo Bozano, from the Department of Morphology of the São Paulo State University (UNESP), Botucatu, SP, for the excellent technical assistance. The authors would also like to thank José Carlos Georgete for the help in diet preparation. Finally, authors are grateful to The State of São Paulo Research Foundation (FAPESP) and The National Council for Scientific and Technological Development (CNPq), for the financial support.

\section{Author details}

${ }^{1}$ Graduate Program in Cell and Structural Biology, Institute of Biology, University of Campinas (UNICAMP), Campinas, SP, Brazil. ${ }^{2}$ Department of Morphology, Institute of Biosciences, UNESP - Univ Estadual Paulista, Botucatu, SP, Brazil. ${ }^{3}$ Medical Clinic Department, Botucatu Medical School, UNESP - Univ Estadual Paulista, Botucatu, SP, Brazil.

\section{Authors' contributions}

All authors participated in the design, interpretation of the studies, analysis of the data and review of the manuscript; CDBF, GSAF, FFB, APF and JEP conducted the experiments; CDBF and WDGK wrote the manuscript. This study represents part of CDBF Ph.D. thesis presented to the State University of Campinas, under the advisory of WDGK. All authors read and approved the final manuscript.

\section{Competing interests}

The authors declare that they have no competing interests.

Received: 2 December 2010 Accepted: 11 March 2011

Published: 11 March 2011

\section{References}

1. Morris MJ, Velkoska E, Cole TJ: Central and peripheral contributions to obesity-associated hypertension: impact of early overnourishment. Exp Physiol 2005, 90(5):697-702.

2. Chavarro JE, Toth TL, Wright DL, Meeker JD, Hauser R: Body mass index in relation to semen quality, sperm DNA integrity, and serum reproductive hormone levels among men attending an infertility clinic. Fertil Steril 2010, 93(7):2222-2231.

3. Power ML, Schulkin J: Sex differences in fat storage, fat metabolism, and the health risks from obesity: possible evolutionary origins. Br J Nutr 2008, 99(5):931-940.

4. WHO - World Health Organization: Part I: The problem of overweight and obesity. World Health Organization. Obesity: preventing and managing the global epidemic Geneva: WHO Technical Report Series; 2000, 894.

5. Nammi S, Koka S, Chinnala KM, Boini KM: Obesity: An overview on its current perspectives and treatment options. Nutr J 2004, 3:3.

6. Mayes JS, Watson GH: Direct effects of sex steroid hormones on adipose tissues and obesity. Obes Rev 2004, 5(4):197-216

7. Pasquali R, Pelusi C, Genghini S, Cacciari M, Gambineri A: Obesity and reproductive disorders in women. Hum Reprod Update 2003, 9(4):359-372.

8. Robker RL: Evidence that obesity alters the quality of oocytes and embryos. Pathophysiology 2008, 15(2):115-121.

9. Hammoud AO, Wilde N, Gibson M, Parks A, Carrell DT, Meikle W: Male obesity and alteration in sperm parameters. Fertil Steril 2008, 90(6):2222-2225

10. Magnusdottir EV, Thorsteinsson T, Thorsteinsdottir S, Maria Heimisdottir M, Olafsdottir K: Persistent organochlorines, sedentary occupation, obesity and human male subfertility. Hum Reprod 2005, 20(1):208-215.

11. Jensen TK, Andersson AM, Jørgensen N, Andersen AG, Carlsen $E$, Petersen JH, Skakkebæk NE: Body mass index in relation to semen quality and reproductive hormones among 1,558 Danish men. Fertil Steril 2004, 82(4):863-870.

12. Kort HI, Massey JB, Elsner CW, Mitchell-Leef D, Shapiro DB, Witt MA Roudebush WE: Impact of Body Mass Index Values on Sperm Quantity and Quality. J Androl 2006, 27(3):450-452.
13. Aggerholm AS, Thulstrup AM, Toft G, Ramlau-Hansen CH, Bonde JP: Is overweight a risk factor for reduced semen quality and altered serum sex hormone profile? Fertil Steril 2008, 90(3):619-626.

14. Archer ZA, Mercer JG: Brain responses to o besogenic diets and dietinduced obesity. Proc Nutr Soc 2007, 66(1):124-130.

15. Tan HM, Gundlach AL, Morris JM: Exaggerated feeding response to central galanin-like peptide administration in diet-induced obese rats. Neuropeptides 2005, 39(3):333-336.

16. Ghanayem Bl, Bai R, Kissling GE, Travlos G, Hoffler U: Diet-induced obesity in male mice is associated with reduced fertility and potentiation of acrylamide-induced reproductive toxicity. Biol Reprod 2010, 82(1):94-104.

17. Bakos HW, Mitchell M, Setchell BP, Lane M: The effect of paternal dietinduced obesity on sperm function and fertilization in a mouse model. Int J Androl 2010.

18. Tortoriello DV, McMinn J, Chua SC: Dietary-induced obesity and hypothalamic infertility in female DBA/2J mice. Endocrinology 2004, 145(3):1238-1247.

19. Mandenoff $A$, Bertière $M C$, Betoulle $D$, Apfelbaum M: Action of naltrexone on the sexual impairment of obese cafeteria rats. NIDA Res Monogr 1986, 75:489-492.

20. Nascimento AF, Sugizaki MM, Leopoldo AS, Lima-Leopoldo AP, Luvizotto RAM, Nogueira CR, Cicogna AC: A hypercaloric pellet-diet cycle induces obesity and co-morbidities in Wistar rats. Ara Bras Endocrinol Metabol 2008, 52(6):968-974.

21. Francia-Farje LAD, Silva DS, Volpato GT, Fernandes GSA, Carnietto N, Cicogna AC, Kempinas WG: Sibutramine effects on the reproductive performance of pregnant overweight and non-overweight rats. J Toxicol Environ Health A 2010, 73(13-14):985-990.

22. Taylor BA, Phillips SJ: Detection of obesity QTLs on mouse chromosomes 1 and 7 by selective DNA pooling. Genomics 1996, 34(3):389-398.

23. Robb GW, Amman RP, Killian GJ: Daily sperm production and epididymal sperm reserves of puberal and adult rats. J Reprod Fertil 1978, 54(1):103-107.

24. Fernandes GS, Arena AC, Fernandez CDB, Mercadante A, Barbisan LF, Kempinas WG: Reproductive effects in male rats exposed to diuron. Reprod Toxicol 2007, 23(1):106-112.

25. Ahlenius S, Larsson K: Apomorphine and haloperidol-induced effects on male rat sexual behavior: no evidence for actions due to stimulation of central dopanine autoreceptors. Pharmacol Biochem Behav 1984, 21(3):463-466

26. Ågmo A: Male rat sexual behavior. Brain Res Protoc 1997, 1(2):203-209,

27. Seed J, Chapi RE, Clegg ED, Dostal LA, Foote RE, Hurtt ME, Klinefelter GR, Makris SL, Perreault SD, Schrader S, Seyler D, Sprando R, Treinen KA, Rao Veeramachaneni DN, Wise LD: Methods for assessing sperm motility, morphology, and counts in the rat, rabbit, and dog: a consensus report. Reprod Toxicol 1996, 10(3):237-244.

28. Filler R: Methods for evaluation of rats epididymal sperm morphology. In Male reproductive toxicology. Edited by: Chapin RE, Heindel JH. San Diego, California: Academic Press, Inc; 1993:334-343

29. Laskey JW, Klinefelter GR, Kelce WR, Ewing LL: Effect of ethane dimethanesulphonate on adult and immature rabbit Leydig cells: comparison with EDS treated rat Leydig cells. Biol Reprod 1994, 50(5):1151-1160.

30. Amann RP: The use of animal models for detecting specific alterations in reproduction. Fundam Appl Toxicol 1982, 2(1):13-26.

31. Klinefelter GR: Actions of toxicants on the structure and function of the epididymis. In The Epididymis - from molecules to clinical pratice. 1 edition. Edited by: Robaire B, Hinton BT. New York: Kluwer Academic/Plenum Publisher: 2002:353-369.

32. Klinefelter GR, Laskey JW, Kelce WR, Ferrell J, Roberts NL, Suarez JD, Slott V: Chloroethylmethanesulfonate-induced Effects on the Epididymis seem unrelated to altered Leydig Cell Function. Biol Reprod 1994, 51(1):82-91.

33. Kempinas WG, Suarez JD, Roberts NL, Strader L, Ferrell J, Goldman JM, Narotsky MG, Perreault SD, Evenson DP, Ricker DD, Klinefelter GR: Fertility of rat epididymal sperm after chemically and surgically induced sympathectomy. Biol Reprod 1998, 59(4):897-904.

34. Hammoud AO, Gibson M, Peterson CM, Hamilton BD, Carrell DT: Obesity and male reproductive potential. J Androl 2006, 27(5):619-626.

35. Viqueras-Villaseñor RM, Rojas-Castañeda JC, Chávez-Saldaña M, Gutiérrez Pérez O, García-Cruz ME, Cuevas-Alpuche O, Reyes-Romero MM, Zambrano E: Alterations in the spermatic function generated by obesity in rats. Acta Histochem 2011, 113(2):214-20. 
36. West DB, York B: Dietary fat, genetic predisposition, and obesity; lessons from animal models. Am J Clin Nutr 1998, 67(3 suppl):505S-512S

37. Ramirez I, Friedman Ml: Dietary hyperphagia in rats: role of fat, carbohydrate, and energy content. Physiol Behav 1990, 47(6):1157-1163.

38. Schrauwen $P$, Westerterp KR: The role of high-fat diets and physical activity in the regulation of body weight. Br J Nutr 2000, 84(4):417-427.

39. Tentolouris N, Pavlatos S, Kokkinos A, Perrea D, Pagoni S, Katsilambros N: Diet-induced thermogenesis and substrate oxidation are not different between lean and obese women after two different isocaloric meals, one rich in protein and one rich in fat. Metabolism 2008, 57(3):313-320.

40. WHO - World Health Organization: Physical status: the use and interpretation of antromometry. Report of a WHO Expert Committee Geneva: World Health Organization; 1995, (WHO Technical Report Series, No. 854).

41. Jeyakumar SM, Lopamudra P, Padmini S, Balakrishna N, Giridharan NV, Vajreswari A: Fatty acid desaturation index correlates with body mass and adiposity indices of obesity in Wistar NIN obese mutant rats strains WNIN/Ob and WNIN/GR-Ob. Nutr Metab 2009, 6:27.

42. Aizawa-Abe M, Ogawa Y, Masuzaki H, Ebinara K, Satoh N, Iwai H, Matsuoka N, Hayashi T, Hosoda K, Inoue G, Yoshimara Y, Nakao K: Pathophysiological role of leptin in obesity-related hypertension. J Clin Invest 2000, 105(9):1243-1252

43. Tena-Sempere M, Manna PR, Zhang FP, Pinilla L, González LC, Diéguez C, Huhtaniemi I, Aguilar E: Molecular mechanisms of leptin action in adult rat testis: potetial targets for leptin-induced inhibition of steroidogenesis and pattern of leptin receptor Messenger ribonucleic acid expresission. Endocrinol 2001, 170(2):413-423.

44. Olivares A, Méndez JP, Zambrano E, Cárdenas M, Tovar A, Perera-Marín G, Ulloa-Aguirre A: Reproductive axis function and gonadotropin microheterogeneity in a male rat model of diet-induced obesity. Gen Comp Endocrinol 2010, 166(2):356-364.

45. Tena-Sempere $M$, Barreiro ML: Leptin in male reproduction: the testis paradigm. Mol Cell Endocrinol 2002, 188(1-2):9-13.

46. Farley C, Cook JA, Spar BD, Austin TM, Kowalski TJ: Meal pattern analysis of diet-induce obesity in susceptible and resistant rats. Obes Res 2003, 11(7):845-851

47. Fam BC, Morris MJ, Hansen MJ, Kebede M, Andrikopoulos S, Proietto J, Thorburn AW: Modulation of central leptin sensitivity and energy balance in rat model of diet-induced obesity. Diabetes Obes Metab 2007 9(6):840-852

48. Edmonds ES, Dallie SK, Withyachumnarnkul B: Reproductive System of the Obese Male Zucker Rat. Reproductive Capacity, Artificial Insemination and Plasma Testosterone Levels. Biol Reprod 1982, 27(4):891-897.

49. Syntin $P$, Robaire $B$ : Sperm structural and motility changes during aging in the Brown Norway rat. J Androl 2001, 22(2):235-244.

50. Auroux M, Nawar NN, Rizkalla N: Testicular aging: vascularization and gametogenesis modifications in the Wistar rat. Arch Androl 1985, 14(23):115-121.

51. Ashby J, Tinwell H, Lefevre PA, Joiner R, Haseman J: The effect on sperm production in adult Sprague-Dawley rats exposed by gavage to bisfenol A between postnatal days 91-97. Toxicol Sci 2003, 74(1):129-138.

52. Fernandez CDB, Porto EM, Arena AC, Kempinas WG: Effects of altered epididymal sperm transit time on sperm quality. Int J Androl 2007, 31:427-437.

53. Giagulli VA, Kaufman JM, Vermeulen A: Pathogenesis of the decreased androgen levels in obese men. J Clin Endocrinol Metab 1994, 79(4):997-1000.

54. Mahadevan MM, Trounson AO: The influence of seminal characteristics on the sucess rate of human in vitro fertilization. Fertil Steril 1984, 42(3):400-405.

55. Bostofte E, Bagger P, Michael A, Stakemann G: Fertility prognosis for infertile men from two different population evoluated by the Cox regression model. Fertil Steril 1990, 54(6):1100-1106.

56. Barratt CL, Tomlinson MJ, Cooke ID: Prognostic significance of computerised motility analysis for in vivo fertility. Fertil Steril 1993, 60(3):520-525.

57. Brooks DE: Epididymal functions and their hormonal regulation. Aust J Biol Sci 1983, 36(3):205-221.

58. Cooper TG: Epididymis. In Encyclopedia of Reproduction. Volume 2. Edited by: Knobil E \& Neill JD. California: Academic Press; 1998:1-17.
59. Jones RC: To store or mature spermatozoa? The primary role of the epididymis. Int J Androl 1999, 22(2):57-67.

60. Gatti JL, Castella S, Dacheux F, Ecruyd H, Métayer S, Thimon V, Dacheux UL: Post-testicular sperm environment and fertility. Anim Reprod Sci 2004, 8283:321-339.

61. Sullivan R, Saez F, Girouard J, Frenette G: Role of exossomes in sperm maturation during the transit along the male reproductive tract. Blood Cells Mol Dis 2005, 35(1):1-10.

62. Orgebin-Crist MC, Tichenor PL: Effect of testosterone on sperm maturation in vitro. Nature 1973, 245:328-329.

63. Henderson NA, Robaire B: Effects of PNU157706, a dual 5a-reductase inhibitor, on rat epididymal sperm maturation and fertility. Biol Reprod 2005, 72(2):436-443.

64. Aitken RJ, Sutton M, Waner P, Richardson DW: Relationship between the moviment characteristics of human spermatozoa and their ability to penetrate cervical mucus and zona-free hamsters oocytes. J Reprod Fertil 1985, 73(2):441-449.

65. Feneux D, Serres C, Jouannet P: Sliding spermatozoa: a dyskinesia responsible for human infertility? Fertil Steril 1985, 44(4):508-511.

66. Mortimer D, Pandya IJ, Sawers RS: Relationship between human sperm motility characteristics and sperm penetration into human cervical mucus in vitro. J Reprod Fertil 1986, 78(1):93-102.

67. Donnelly ET, Lewis SEM, McNally JA, Thompson W: In vitro fertilization and pregnancy rates: the influence of sperm motility and morphology on IVF outcome. Fertil Steril 1998, 70(2):305-314

68. Plassmann $\mathrm{S}$, Urwyler $\mathrm{H}$ : Improved risk assessment by screening sperm parameters. Toxicol Lett 2001, 119(2):157-171.

69. U.S.EPA-United State Environmental Protection Agency: Reproductive Toxicity Risk Assessment Guidelines 1996

70. Pascuali R: Obesity, fat distribution and infertility. Maturitas 2006, 54(4):363-371

71. Klinefelter GR, Laskey JW, Perreault SD, Ferrel J, Jeffay S, Suarez J, Roberts N: The ethane dimethanesulphonate-induced decrease in the fertilizing ability of cauda epididymal sperm is independent of the testis. J Androl 1994, 15(4):318-327.

72. Perreault SD, Cancel AM: Significance of incorporating measures of sperm production and function into rat toxicology studies. Reproduction 2001, 121(2):207-216.

doi:10.1186/1477-7827-9-32

Cite this article as: Fernandez et al:: Diet-induced obesity in rats leads to a decrease in sperm motility. Reproductive Biology and Endocrinology 2011 9:32.

\section{Submit your next manuscript to BioMed Central and take full advantage of:}

- Convenient online submission

- Thorough peer review

- No space constraints or color figure charges

- Immediate publication on acceptance

- Inclusion in PubMed, CAS, Scopus and Google Scholar

- Research which is freely available for redistribution

Submit your manuscript at www.biomedcentral.com/submit
C Biomed Central 